\title{
Automation Anxieties: \\ Perceptions About Technological Automation and the Future of Pharmacy Work
}

\author{
Cameron W. Piercy ${ }^{1}$ (i) and Angela N. Gist-Mackey ${ }^{1}$ \\ 1 Communication Studies Department, University of Kansas, Lawrence, KS, USA
}

\begin{abstract}
This study uses a sample of pharmacists and pharmacy technicians $(N=240)$ who differ in skill, education, and income to replicate and extend past findings about socioeconomic disparities in the perceptions of automation. Specifically, this study applies the skills-biased technical change hypothesis, an economic theory that low-skill jobs are the most likely to be affected by increased automation (Acemoglu \& Restrepo, 2019), to the mental models of pharmacy workers. We formalize the hypothesis that anxiety about automation leads to perceptions that jobs will change in the future and automation will increase. We also posit anxiety about overpayment related to these outcomes. Results largely support the skillsbiased hypothesis as a mental model shared by pharmacy workers regardless of position, with few effects for overpayment anxiety.
\end{abstract}

Keywords: automation, future of work, mental models, pharmacy, structural equation modeling

\section{Introduction}

Human-technology collaboration is ubiquitous in modern organizational contexts. Today's workers rely heavily on technology to remain connected, to schedule meetings, coordinate tasks, and collaborate with others (Colbert et al., 2016). Certain industries are embracing increased automation as part of everyday work. For instance, the pharmacy sector has

CONTACT Cameron W. Piercy (D) - Communication Studies Department • University of Kansas • 1440 Jayhawk Blvd. Room 102 • Lawrence, KS 66044 • cpiercy@ku.edu 
embraced automation in order to improve efficiency and reduce errors in the often-tedious task of filling prescriptions. According to Gebhart (2019), "dispensing robots free up pharmacists and technicians for more profitable clinical services that require human judgment" (para. 1). There are many reasons why industries might favor automation, computers, and artificial intelligence over human labor. Capable machines can complete repetitive and dangerous work, they do not strike (Taipale et al., 2015), show up late, need time off, and generally pay for themselves (West, 2018). Further, while the average factory worker costs more than $\$ 36 /$ hour, robots costs as little as $\$ 4 /$ hour to operate (Wike \& Stokes, 2018). Despite the organizational benefits, employees often view technology as potentially job threatening.

Complex technologies are fundamentally changing the scope and structure of human work. As Edwards et al. (2019) contend, "current trends suggest a near future characterized by more common, normalized, and sustained interactions between people and social robots" (p. 312). Advanced technological machines will continue to reshape the labor market by changing jobs, replacing positions, and generally altering the nature of work (Acemoglu \& Restrepo, 2019). Thus, researchers must ask: How do employees perceive the future of human-technology collaboration?

This study seeks to test how pharmacy workers conceive of automation and computerization at work. Specifically, we test the skills-biased technical change hypothesis (SBTC hypothesis), the prediction that low-skill work is the most likely to change or be replaced as computerization and automation increases (Berman et al., 1998; Frey \& Osborne, 2017), in a situated pharmacy context where education, income, and skill vary according to role (i.e., pharmacists and pharmacy technicians). This study builds on past evidence to elucidate the mental models of both fear of automation and perceptions that one's work will change or be replaced by machines in the future.

Mental models, the "dynamic cognitive frameworks representing spatial, systemic, causal, or situational phenomena" (Banks, 2020, p. 2), serve as frames for interpreting the world. Preconceptions about machines serve as inflection points for decision, choice, and action with regard to both novel and well-known stimuli (Spence et al., 2018). As Banks (2020) succinctly explains, "mental models are sets of ideas for what the world is, how it works, how it unfolds, or what happens in it, and these ideas are used to describe, explain, and predict events or things in the world" (p. 2). Mental models are useful for considering machine communication partners because they encompass social norms, orientations toward machines, and other considerations of how technology has, might, or ought to be used (Mantovani, 1996). Because they are based on a social conception of reality, mental models are connected to and often precede communication behaviors (Fairhurst, 2010). In short, mental models shape and are shaped by communication.

We explore mental models about automation in a sample of pharmacists and pharmacy technicians who, despite working side-by-side, have highly discrepant education, income, and skill-requirements (Wheeler et al., 2019). This sample is ideal because pharmacies have long embraced automation practices (Hynniman \& Lamy, 1967; Madden \& Dreyfus, 1968), and pharmacies represent an environment marked by high demand for efficiency, role clarity, collaboration, and increasingly, human-machine communication (HMC; Albanese et al., 2010). Further, the pharmacy sector is a compelling context because this sector is increasingly adopting automation to reduce errors, improve productivity, and yield better patient care (Barrett et al., 2012). This study reveals how perceptions of machines manifests 
in everyday work for pharmacy workers. Below we review relevant literature, introduce research questions and hypotheses, and report findings. We conclude with a discussion and recommendations based on findings from this unique sample regarding HMC and focusing on the role of mental models, feelings of anxiety, and perceptions of the future of work.

\section{The Skill-Biased Technical Change (SBTC) Hypothesis}

Economists do not agree about how automation will alter the future of work. The predominant hypothesis is the skill-biased technical change hypothesis (SBTC hypothesis; Berman et al., 1998; Frey \& Osborne, 2017). The SBTC hypothesis posits that due to automation lower skill jobs will be the most susceptible to change, more likely to be eliminated, and pay inequality will increase in the future. Alternatively, some studies also frame the hypothesis as an increased demand for high-skill jobs (Autor, 2015). For example, Frey and Osborne forecasted that half of occupations are susceptible to automation, based on the complexity of job descriptions.

Though some have argued the SBTC hypothesis is wrong (for discussion, see Frank et al., 2019), the basic premise, that deskilled positions involving simple and repetitive tasks will be increasingly automated, generally holds (Brynjolfsson \& Mitchell, 2017). However, there is a "lack of empirically informed models of key microlevel processes" including how people interact with, adapt to, and conceptualize automation (Frank et al., 2019, p. 6531). Our study fills this gap by exploring how American pharmacy workers feel about current and impending automation. We offer insights into how technology might be adopted/ avoided by the contemporary labor force.

Historically, the adoption of new technologies in face-to-face relationships has garnered widespread skepticism, which Baym (2015) calls moral panic. From the printing press to the internet, humans tend to both assume and internalize the negative effects of new technologies on relational outcomes-despite a breadth of evidence suggesting otherwise (Green \& Clark, 2015). This is no different for advanced work technologies. Overall, people are quite concerned about machines potentially taking jobs. For example, Google-searching "will robots..." yields autofill responses of "take my job," "take over the world," "replace humans," and other concerning outcomes. Further, European residents "overwhelmingly fear job displacement from robots" (Taipale \& Fortunati, 2018, p. 201) as do people in nearly every country surveyed (Wike \& Stokes, 2018). Anxieties about automation also prompt an introspective bias, whereby people broadly believe automation, robots, or computers will replace human work, yet feel their own jobs are less susceptible (Geiger, 2019).

Views about robots, artificial intelligence (AI), and automation are often related to science-fiction portrayals of robots and artificial intelligence (see Horstmann \& Krämer, 2019). For instance, Liang and Lee (2017) found that fear of autonomous robots and artificial intelligence was related to exposure to media and negatively associated with education and income. Using a continent-wide sample of Europeans, Taipale and Fortunati (2018) found that those who were more educated with higher incomes were more likely to see their jobs as more secure in light of increased automation (see also, Turja \& Oksanen, 2019). Moreover, income and education are positively related to concerns about automation in representative U.S. samples (Smith, 2016). 


\section{Automation in Pharmacies}

Pharmacies, especially large retail chains, are blending "artificial intelligence, machine learning, and advanced software engineering to enhance operational resilience and boost productivity" (BusinessWire, 2020, para. 2). Automation is incorporated in pharmacies in many ways including "record keeping, item selection, labeling, and dose packing" (Spinks et al., 2017, p. 394). Both hospital and retail pharmacies may reconfigure the behind-thecounter workspace for machines (Barrett et al., 2012; Chapuis et al., 2010). But machines are also often placed at centralized distant sites to pre-fill bottles for retail locations (Spinks et al., 2017).

Today, automation in pharmacies is valued at $\$ 5.1 \mathrm{bn}$ USD and is expected to reach $\$ 7.8$ bn USD by 2024 (Elder, 2019); this increase is largely due to reduced errors and faster fill times. Human error can create a tremendous cost for pharmacies, including unnecessary illness and even loss of life. Human errors occur at a rate of approximately 5 errors per 100,000 orders (Gorbach et al., 2015). But automated prescription filling has error rates near zero (Fanning et al., 2016; cf., Chapuis et al., 2010) and significantly decreases prescription filling time (Walsh et al., 2011).

This bottom-line decision-making focused on operations and productivity likely shapes the organizational reality faced by pharmacy workers, especially those whose roles require less skill (i.e., technicians; Wheeler et al., 2019). Pharmacists and pharmacy technicians have differentiated skill sets, education, and incomes. Thus, pharmacy workers offer a salient sample with differing socioeconomic positions to explore feelings of anxiety tied to automation.

While HMC has been studied during automation implementation in pharmacies (see Barrett et al., 2012), we focus on mental models about automation because mental models guide and are guided by communication (Fairhurst, 2010). Thus, we explore how pharmacy workers think about automation in pharmacy labor. Specifically, we hypothesize differences in automation anxiety and overpayment anxiety will influence perceptions that automation will increase in the future, that pharmacy work will change in the future, and that automation is helpful in pharmacy work.

\section{Roles in the Pharmacy}

Following the SBTC hypothesis, we analyze two divergent socioeconomic groups: pharmacy technicians and pharmacists. Each role contributes to pharmacy work in different ways. Pharmacy technicians operate "under the supervision of the licensed pharmacist, [and] assists in pharmacy activities that do not require the professional judgment of a pharmacist" (Albanese et al., 2010, p. e55). The technician's role is juxtaposed alongside robotic interventions: "Along with robotic dispensing technology, [technician] support enables pharmacists to play a more proactive and expanded role in patient care" (p. e36). Pharmacy technicians are typically hourly workers, with less formal training, who assist pharmacists.

Conversely, the role of pharmacists is typically broader with a focus on judgment, decision-making, consultation, and supervising. Pharmacists are expected to manage their units, supervise personnel, administer medications, ensure the pharmacotherapy matches the patients' needs, and that the patient understands treatment (Albanese et al., 2010). In addition to formal education, pharmacists are also responsible for maintaining regulated 
competencies to meet patient needs. In all, though both roles are well-defined, pharmacists are expected to maintain a higher level of skill relative to pharmacy technicians. This hierarchical, educational, monetary, and expertise-driven difference positions pharmacy technicians as lower-skilled workers and pharmacists as skilled experts. If the SBTC hypothesis holds, technology ought to affect pharmacy technicians' mental models more than pharmacists. Given these discrepancies we propose that in mental models regarding the future of automation and pharmacy work:

H1: Pharmacy technicians will report higher automation anxiety than pharmacists.

H2: Automation anxiety will be positively related to perceptions that (a) the pharmacy job will change across time, (b) automation will increase across time, and (c) automation is helpful to pharmacy work.

Some estimates suggest the probability of pharmacists being replaced by automation is extremely low (.00003) while the probability for replacing pharmacy technicians is quite high (0.92; Frey \& Osborne, 2017). Ironically, the $\mathrm{O}^{\star} \mathrm{Net}$ database maintained by the U.S. Department of Labor, which was used as the source for job descriptions in Frey and Osborne's study, classifies pharmacy technicians as a "bright outlook" occupation (onetonline.org, 2020). Frey and Osborne's (2017) study supports the SBTC hypothesis, but it remains unknown how people who work in the same environment, yet have differing skill, pay, and expertise might view automation and the future of their industry. Given the difference in roles taken on by pharmacists and pharmacy technicians, and the predictions by SBTC hypothesis, we ask how these two groups might differ regarding perceptions of future automation in the industry, the benefits of automation, and perceptions that pharmacy jobs will change over time:

RQ1: How do pharmacists and pharmacy technicians differ in terms of (a) perceptions that automation will increase in the coming years, (b) perceived helpfulness of automation, and (c) perceptions that their job will change in the coming years?

Driven by capitalistic market pressures, many industries seek to reduce costs. Technological advancements, like automation, have often been a strategy to deskill work. While this is typically seen as a direct threat to low-income workers, Littler and Innes (2003) found that it also threatens knowledge workers, those with high levels of expertise. In fact, downsizing as a cost-saving effort weakens the job stability of those who are highly compensated and highly educated. This phenomenon has been called deknowledging the workforce and leads to a hollowing out of organizations by thinning out those who are well-paid at the top of the organizational hierarchy, like pharmacists (Frank et al., 2019; Littler \& Innes, 2003).

Pharmacists likely view automation as a boon to their work, given the guidance that pharmacists ought to leverage pharmacy technicians and automation processes to boost productivity. However, there has been speculation that dramatic increases in automation processes could threaten pharmacists' jobs as well (Spinks et al., 2017). Spinks et al. point out that automation is typically implemented in a decentralized hub-and-spoke system 
which physically displaces the jobs remaining. Given the pay discrepancies which pervade the pharmacy environment, it is logical pharmacists might worry about their high pay as a potential liability in light of sophisticated automation. Specifically, while the median wage for pharmacists is greater than $\$ 100,000$ per year (Polgreen et al., 2011), the median wage for a pharmacy technician is $\$ 15$ per hour $(\$ 31,200$ per year for a full-time employee; Wheeler et al., 2019). Further, technicians often work in part-time roles and largely report dissatisfaction with their pay (Desselle \& Holmes, 2017). This substantial discrepancy likely affects how both parties view their work and perceive the way automation will affect their career paths. While technicians might perceive pay insufficiency, it is more likely that pharmacists view their salary as a liability. We hypothesize:

H3: Overpayment anxiety will be positively related to perceptions that (a) the pharmacy job will change across time, (b) automation will increase across time, and (c) automation is helpful to pharmacy work.

H4: Pharmacists will experience greater overpayment anxiety than pharmacy technicians.

\section{Method}

\section{Sample}

This research was done in partnership with a state-level pharmacists association. To begin recruitment, the state-level pharmacy association shared the study on its member listserv and permitted us to recruit onsite at their annual conference. We also shared the survey on the Reddit group r/talesfromthepharmacy, visited local pharmacies with flyers, and recruited online with permission on several Facebook and LinkedIn groups dedicated to pharmacy practice. In total we report findings from 131 pharmacists and 109 pharmacy technicians. Just under half of the sample was from Kansas $(n=117,47.4 \%)$ with the remainder from 35 different states.

As expected, pharmacists $(M=11.52, S D=2.12)$ and pharmacy technicians $(M=4.95$, $S D=2.75$ ) reported very different household incomes (range: $1=$ under $\$ 10,000$ to $13=$ $\$ 150,000$ or more $), t_{\text {corrected }}(224)=2.17, p<.001, d_{\text {Cohens }}=2.68$. Pharmacists $(M=5.43, S D=$ $0.90)$ had higher education levels than pharmacy technicians $(M=3.26, S D=1.00 ; 1=$ less than H.S. degree, $6=$ doctoral degree $), t_{\text {corrected }}(224)=17.73, p<.001, d_{\text {Cohens }}=2.28$. Three quarters of participants were female $(n=184,76.7 \%)$ and most identified as White $(n=229$, 95.4\%). Participants' ages ranged from 20 to 80 years $(M=38.15, S D=12.07)$.

\section{Measures}

Measures were based on pre-existing items when possible; we began by adding additional items to questions posed by Pew Research (Smith, 2016). To reduce participant burden, and because participants were uncompensated, we used concise measures when possible. Though our measures represent incomplete or limited mental model content, it is reasonable that these measures likely reflect more broadly held assumptions or expectations (Edwards et al., 2019) about machines (e.g., tension, fearfulness, stress, negativity, danger; 
Spence et al., 2018). We modified items to fit the pharmacy environment when appropriate. Unless otherwise noted, scales were measured on a Likert-type scale where $1=$ strongly disagree and 7 = strongly agree. Table 1 presents correlations among demographics and the variables of interest.

TABLE 1 Correlations, Pooled Means, and SDs, Among Study Variables

\begin{tabular}{|l|c|c|c|c|c|c|c|c|c|c|}
\hline & M & SD & 1. & 2. & 3. & 4. & 5. & 6. & 7. & 8. \\
\hline 1. Income & 8.59 & 4.05 & - & & & & & & & \\
\hline 2. Education & 4.38 & 1.41 & $0.66^{* * *}$ & - & & & & & & \\
\hline 3. Age & 38.15 & 12.07 & $0.32^{* * *}$ & $-0.13^{*}$ & - & & & & & \\
\hline $\begin{array}{l}\text { 4. Automation } \\
\text { Anxiety }\end{array}$ & 3.28 & 1.49 & $-0.19^{* *}$ & $-0.17^{* *}$ & -0.03 & - & & & & \\
\hline $\begin{array}{l}\text { 5. Overpayment } \\
\text { Anxiety }\end{array}$ & 4.20 & 1.96 & 0.08 & 0.10 & 0.09 & $0.42^{* * *}$ & - & & & \\
\hline $\begin{array}{l}\text { 6. Increased } \\
\text { Automation }\end{array}$ & 3.67 & 1.72 & 0.05 & -0.02 & 0.11 & $0.36^{* * *}$ & $0.13^{*}$ & - & & \\
\hline 7. Job Change & 5.74 & 1.70 & 0.09 & 0.07 & -0.07 & $-0.38^{* * *}$ & $-0.28^{* * *}$ & $-0.26^{* * *}$ & - & \\
\hline $\begin{array}{l}\text { 8. Automation } \\
\text { Helpfulness }\end{array}$ & 4.78 & 1.52 & $0.19^{* *}$ & $0.20^{* *}$ & 0.04 & $-0.24^{* * *}$ & $-0.21^{* *}$ & 0.07 & 0.08 & - \\
\hline
\end{tabular}

Note: $N=240$, two participants did not report their age. Each scale is detailed under Sample and Measures above. $p<.05^{*}, p<.01^{* *}, p<.001^{* * *}$

\section{Automation Anxiety}

To measure feelings of automation anxiety, we used the stem prompt: "I am concerned about losing my job because" with four items: "My employer might use machines or computer programs to replace human workers," "Automation could lead to a reduction in the number of workers needed to do my job," "The job I do today could be done by machines tomorrow," and "Robotic devices could replace people in my role." The scale was reliable, $\alpha=.86$.

\section{Overpayment Anxiety}

We hypothesized that feelings of overpayment anxiety would operate distinctly from automation anxiety. We used the same stem prompt as in automation anxiety with two items: "My employer might find someone who is willing to do my job for less money," and "Someone who will work for less might be hired into my unit." Though these items highly correlated $\left(R^{2}=0.80, p<.001\right)$, the second item was a Heywood case, the indicator had impossible latent-to-item loadings, in the measurement model $(B>1.00$ among pharmacists; Kline, 2015). The use of only two indicators for a latent factor increases the likelihood of Heywood cases (Kline, 2015). To remedy this, the first item $(M=4.23, S D=2.09)$ was used as a single-item indicator. 


\section{Job Change}

Perceptions that one's job will change were measured with the prompt: "Thinking about your current job and occupation, how likely is it that your job will exist in its current form in" with two time frames: 2 -years and 5 -years. Responses ranged from $1=$ very unlikely to $7=$ very likely. We reverse coded these two items for analysis, they were highly correlated, $R^{2}=0.90, p<.001$.

\section{Increased Automation}

We asked participants: "Overall how likely do you think it is that robotic devices, robots, and computers will do much of the work currently done by humans in" with two time frames: 2 -years and 5 -years. Responses ranged from $1=$ very unlikely to $7=$ very likely. These two items were highly correlated, $R^{2}=.86, p<.001$.

\section{Automation Helpfulness}

To capture the perceived benefits of automation, we developed three semantic-differential items which used 7-points capturing the perceived helpfulness of automation. Specifically, we prompted participants with "Increased use of automation in my workplace would:" with anchors of "Make my job harder | Make my job easier," "Decrease my efficiency | Increase my efficiency," and "Harm me | Help me." These items were reliable, $\alpha=.92$.

\section{Measurement Invariance Testing}

Given the goals of group synthesis and comparison between pharmacists and pharmacy technicians we first assessed our models for measurement invariance, or psychometric equivalence of constructs across groups (Putnick \& Bornstein, 2016). We began by creating an unconstrained configural model in the R package lavaan 0.6-5 (Rosseel, 2012). Configural invariance occurs when "the latent construct has similar meaning" across groups (Kühne, 2013, p. 155). Configural invariance is established through a similar pattern of loadings across groups and sufficient model fit. The initial configural model revealed a Heywood-case indicator, the second overpayment anxiety item. As noted above, we dropped this item and retained the first. Dropping this item is logical because perceptions that one might be replaced by another who works for less money differ dramatically across pay ranges. Subsequent tests of measurement invariance do not apply to this single item indicator for overpayment anxiety. The baseline configural model yields separate $\chi^{2}$ values for each group and a pooled model fit; this configural measurement model fit sufficiently well (Kline, 2015): $\chi_{\text {Pharmacists }}^{2}(90)=56.07, p<.001, \chi^{2} / d f=0.62, \chi_{\text {Technicians }}^{2}(90)=98.86$, $p<.001, \chi^{2} / d f=1.10$, RMSEA $=0.08,90 \%$ CI $[.06, .10]$, SRMR $=0.04$, CFI $=0.96$.

Next, we tested metric invariance, the assumption that "each item contributes to the latent construct to a similar degree across groups" (Putnick \& Bornstein, 2016, p. 75). To test this assumption, indicator loadings were constrained to be equal across the groups before comparing models which were metric invariant: $\chi^{2}(7)=4.66, p=0.70$. Third, we tested scalar invariance, the assumption the latent constructs have the same meaning and "there is no systematic response bias across populations" (Kühne, 2013, p. 154). This model 
constrains both indicator loadings and their intercepts and was scalar invariant: $\chi^{2}(7)=$ $12.19, p=0.09$. Thus, we proceeded with analysis. We use group comparisons to test $\mathrm{H} 1$, RQ1, and H4, then use SEM for H2 and H3.

\section{Results}

\section{Comparing Pharmacists and Pharmacy Technicians}

We first constructed a MANOVA using SPSS 25 to compare pharmacists and pharmacy technicians. Our hypotheses were that pharmacy technicians would have greater automation anxiety ( $\mathrm{H} 1)$, while pharmacists would experience more overpayment anxiety (H4). Further RQ1 asked if these two groups differed in terms of (a) perceptions that automation will increase in the coming years, (b) perceived helpfulness of automation, and (c) perceptions that their job will change in the coming years.

Results of homogeneity of variance as well as normality and multicollinearity assumptions were tested using criteria from Tabachnick and Fidell (2019), no issues were present. The MANOVA was multivariate significant: $F(5,235)=7.14$, Wilks' $\lambda=0.87, p<.001$, $\eta_{\text {partial }}^{2}=0.13$, power $=.999$. Univariate analysis revealed a significant difference in automation anxiety between pharmacy technicians $(M=3.54, S D=1.54)$ and pharmacists $(M=3.04, S D=1.43), F(1,239)=6.82, p=.010, \eta_{\text {partial }}^{2}=0.03$. Thus, $\mathrm{H} 1$, that pharmacy technicians experience greater automation anxiety, was supported.

However, there were no significant differences between pharmacists and technicians in terms of increased automation in the coming years, $F(1,239)=1.13, p=0.289, \eta_{\text {partial }}^{2}=0.01$. Nor was there a difference in terms of perceived job change over time, $F(1,239)=0.29, p=$ $0.594, \eta_{\text {partial }}^{2}=0.00$. Perceptions of automation helpfulness did differ between pharmacists $(M=5.12, S D=1.31)$ and technicians $(M=4.40, S D=1.68), F(1,239)=13.89, p<.001$, $\eta_{\text {partial }}^{2}=0.06$. Thus, the answer to RQ1a-c is that pharmacists and pharmacy technicians do not differ in terms of perceived future automation or job change over the coming 2 and 5 years. However, pharmacists see automation as more useful than do pharmacy technicians.

The final group comparison was for $\mathrm{H} 4$ which contended pharmacists would report higher levels of overpayment anxiety. The univariate tests supported this hypothesis with pharmacists reporting higher overpayment anxiety $(M=4.48, S D=2.04)$ than did technicians $(M=3.94, S D=2.13): F(1,239)=3.91, p=0.049, \eta_{\text {partial }}^{2}=0.02$. Thus, H4 was supported.

\section{Structural Equation Modeling}

To test the remaining hypotheses, we conducted an SEM. This model specifies the relationships presented in $\mathrm{H} 2$ and $\mathrm{H} 3$. We added regression relationships to the measurement model specified above between overpayment and automation anxiety and three outcomes: perceptions that automation will increase, that the job will change in the coming years, and the belief that automation is helpful.

The proposed structural model fit the data sufficiently: $\chi_{\text {Pharmacists }}^{2}(90)=56.07, \mathrm{p}<.001$, $\chi^{2} / d f=0.62, \chi_{\text {Technicians }}^{2}(90)=98.86, p<.001, \chi^{2} / d f=1.10, \operatorname{RMSEA}=.08,90 \%$ CI $[.06, .10]$, $\mathrm{SRMR}=.04, \mathrm{CFI}=0.96$. These values match those presented in the configural measurement model because the relationships among the latent constructs are saturated. 


\section{Pharmacists' Model}

Figure 1 shows pharmacists' feelings of anxiety about automation were positively related to perceptions that the job would include increased automation in the future $(\beta=0.47$, $S E=0.16, p<.001)$ and positively predicted beliefs that the job would change in the future $(\beta=0.40, S E=0.13, p<.001)$. Automation anxiety was negatively related to beneficial automation outcomes, $(\beta=-0.24, S E=0.11, p=.037)$. Thus, $\mathrm{H} 2 \mathrm{a}$ and $\mathrm{b}$ are confirmed among pharmacists. Automation anxieties positively predict perceptions of future automation and job change. Against $\mathrm{H} 2 \mathrm{c}$, pharmacists' automation anxieties were negatively related to perceived benefits of automation.

H3 proposed that overpayment anxieties would predict perceptions that (a) automation will increase in the future, (b) the job will change in the future, and (c) automation is helpful. None of these relationships were significant. Thus, H3 was rejected in the pharmacists' subset.

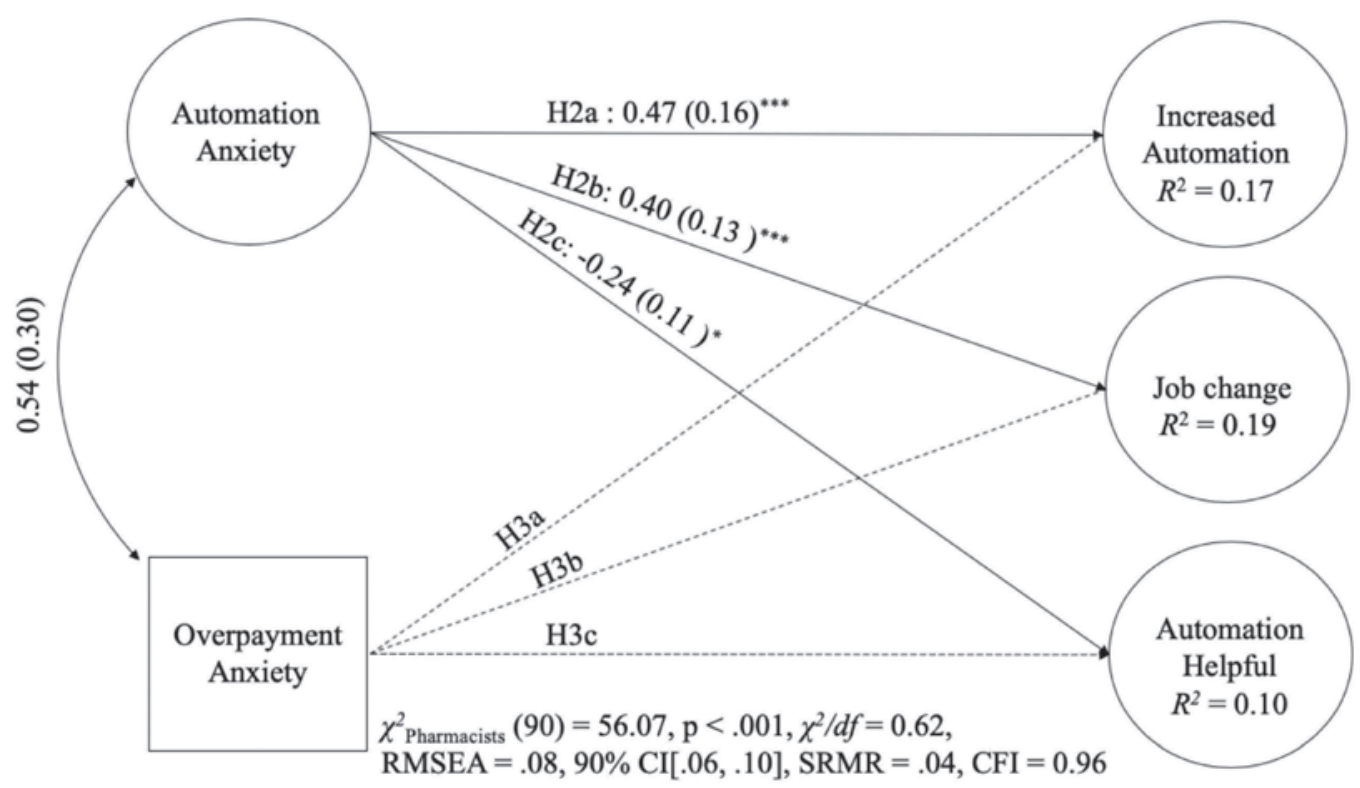

FIGURE 1 Pharmacists' Model

Note: $N=131$ Pharmacists. $p<.05^{*}, p<.001^{* * *}$

\section{Pharmacy Technicians' Model}

Figure 2 shows pharmacy technicians' automation anxiety was positively related to perceptions the job would include increased automation in the future $(\beta=0.46, S E=0.11, p$ $<.001)$, and positively predicted beliefs that the job would change in the future $(\beta=0.38$, $S E=0.12, p=.001)$. However, automation anxiety was unrelated to the perceived helpfulness of automation, $(p=.523)$. Thus, $\mathrm{H} 2 \mathrm{a}$ and $\mathrm{b}$ are confirmed among pharmacy technicians as well. Automation anxieties positively predict perceptions of future automation and job change. Against H2c, technicians' automation anxiety was unrelated to perceived automation benefits. 
In the pharmacy technician's model, $\mathrm{H} 3 \mathrm{a}$ and $\mathrm{b}$ were not supported. However, overpayment anxiety was significantly and negatively related to perceived benefits of automation $(\beta=-0.21, S E=0.08, p=.048)$. Therefore, pharmacy technicians who felt they were overpaid perceived less benefit from automation in the pharmacy. Thus, $\mathrm{H} 3 \mathrm{a}-\mathrm{c}$ is rejected in both the pharmacists and pharmacy technician samples. The full technicians' model is presented in Figure 2.

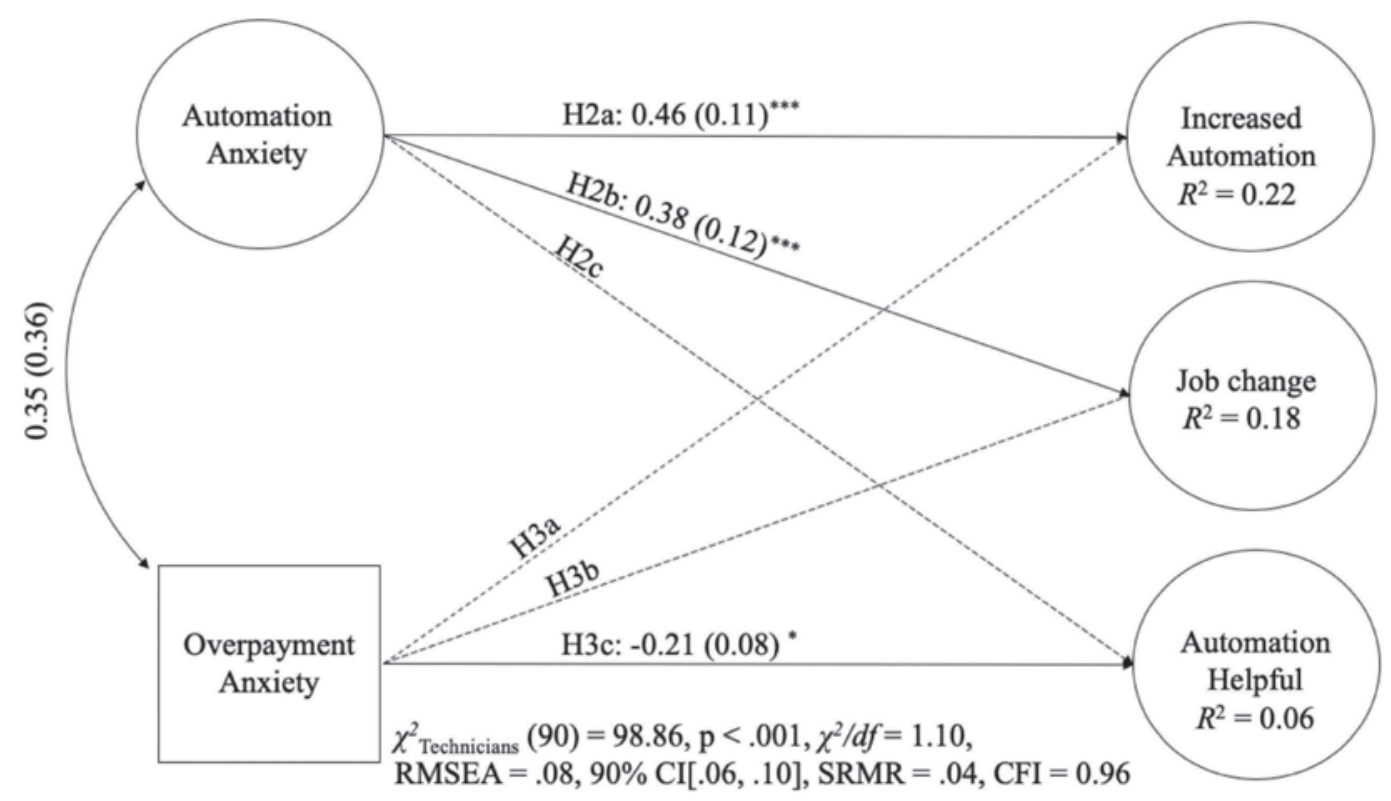

FIGURE 2 Pharmacy Technicians' Model

Note: $N=102$ Pharmacy technicians. $p<.05^{*}, p<.001 * * *$

\section{Discussion}

This study tests the SBTC hypothesis (Acemoglu \& Restrepo, 2019) using a novel sample of pharmacy workers whose education, income, and skills differ by role. Our results juxtapose the SBTC hypothesis against mental models, which drive machine perceptions (Banks, 2020), technology use (Mantovani, 1996), and organizational communication (Fairhurst, 2010). This study adds to previous literature by demonstrating income and education alone are insufficient to determine automation perceptions. Findings reveal pharmacists and pharmacy technicians both experience anxiety related to automation. Despite differing skill, pay, education, and responsibilities, anxiety about automation shapes both parties' view of the future of both automation in pharmacies and future of work in the pharmacy. This is a compelling finding particularly for a sector that is readily adopting automation. Results revealed robust effects for feelings of anxiety about automation with, surprisingly, few effects for overpayment anxiety. These results are intriguing given the differences on key outcomes when comparing pharmacists and pharmacy technicians.

The differences between pharmacists and technicians were significant (accounting for $13 \%$ of variance). Pharmacists and technicians seemed to agree that pharmacy automation 
was likely to increase in the coming years, though this was not significantly different than the scale means for either group. Pharmacists and technicians also agreed that their jobs were likely to change in the coming years, both groups had scale values significantly above the mean $(p<.001)$. Pharmacies are a site rich in job change and automation and these findings show that present anxieties about automation translate into beliefs about the future of work and automation.

Pharmacists and technicians did differ in terms of perceived benefits of automation and overpayment anxieties; pharmacists were more likely to feel overpaid and to see automation as beneficial to their work. This is logical given the pay discrepancies and the clear authority role of pharmacists. Interestingly, pharmacists' anxiety about overpayment did not translate into perceptions their work will change or that automation would increase in coming years.

The next take-away from our study is the relatively straightforward mental-model for automation shared by pharmacists and technicians. The models were identical with two exceptions: pharmacy technicians' overpayment anxiety was related to reduced perceptions of automation helpfulness, whereas pharmacists' automation anxieties were related to perceptions of reduced automation helpfulness. Counter to past findings that automation allows pharmacists to reassert "their privileged position ... while also increasing their institutional legitimacy," (Barrett et al., 2012, p. 1460), these results show both high- and lowskill pharmacy workers share automation anxieties. Feelings of anxiety manifest slightly differently based on position.

We speculate automation anxieties seem to have prompted pharmacists to derogate the benefits of automation (Brehm \& Cohen, 1962), whereas overpayment anxieties seem to have the same effect for pharmacy technicians. These findings regarding pharmacists' automation anxiety likely undergird concerns about deknowledging the pharmacy workforce, while pharmacy technicians' overpayment anxiety seems to reflect concerns about deskilling pharmacy work (Littler \& Innes, 2003). Thus, it is likely each workgroup derogates automations' helpfulness because of varied job security concerns (reduced knowledge and skill requirements, respectively). Both parties anticipate change over time both in their work in a pharmacy and via increased automation. For both, automation anxiety was related to perceived changes. These results signal that while income and education are forces driving automation anxiety in the general population (Liang \& Lee, 2017), in pharmacies, automation anxiety leads to increased beliefs about the changing nature of work and expectations for increased automation. Future, longitudinal, or mixed-methods research could measure and observe perceptions of automation adoption or adaptation over time in order to better understand how mental models change relative to experiences in HMC.

To our knowledge, this is the first test of the SBTC hypothesis based on perceptual data in a recently automated sector. To date, this hypothesis has relied heavily on macro-level models of economic change with little concern about mental models, which shape individuals' everyday communication, interaction, and experiences (Frank et al., 2019). We extend findings from Europe (Taipale \& Fortunati, 2018) and the U.S. (Liang \& Lee, 2017; Smith, 2016) that income and education buffer fears of automation and include perceptions about the future of work. Our findings reveal this hypothesis has translated across socioeconomic groups into pharmacy workers' beliefs about automation and the changes automation brings to their work. 
Further, while other studies have labeled perceptions that automation, computerization, and AI might affect work as a "fear of automation," we choose to label these "feelings of anxiety" to signal the motivational nature of such beliefs. We do not mean to suggest that clinical descriptions of anxiety relate to automation, though they may. Instead, anxiety experienced about major changes to one's work, including the potential for displaced or replaced work, affects the very work practices which combine social and technological counterparts (Barrett et al., 2012). Indeed, feelings of anxiety about new technologies also affects how people adopt, use, and engage with complex machines (Leonardi, 2012). For HMC scholars, these findings reveal how anxieties about machine-communication partners manifest in everyday work practice. It is likely that anxious mental models could foster resistance to HMC, regardless of the benefits technology may offer. Future research would do well to consider the specific manifestations of automation anxiety at work; for example, does anxiety about automation increase/decrease one's effort, satisfaction, or commitment to the workplace? Also, for managers, how might assuring workers' job security amid increased automation affect work outcomes like satisfaction, productivity, or turnover?

For pharmacy workers anxious feelings about automation and the changing nature of work are proximal (i.e., 2 and 5 years) concerns with everyday implications. Indeed, these close temporal estimates about technological and work change were explained quite well by automation anxiety. In addition to the SBTC hypothesis, our study also tests and affirms the proposition that higher-skilled workers also feel vulnerable to technological change (Frank et al., 2019; Littler \& Innes, 2003). Future research could benefit from further consideration of how exposure/adoption in specific industries affects feelings of anxiety about automation, especially as interactions with complex technological co-workers increase (Edwards et al., 2019). In retail environments like grocery store checkouts, medical contexts where algorithms aid diagnoses, and practically every other work domain machine counterparts will increase in use (Frey \& Osborne, 2017).

The derogation of the helpfulness of automation by pharmacists and technicians was unexpected. However, source and message derogation are logical responses to incompatible messages (Brehm \& Cohen, 1962). For these workers, anxieties about automation and overpayment prompted a derogation of the technology that could threaten livelihoods. In line with past research we expect that source and technology derogation affects communication with colleagues and subsequent technological (non)adoption (Leonardi, 2012). To understand how these beliefs form through interaction, future studies might consider networks of HMC interaction.

Given these findings, perceived helpfulness may be tied to outside anxieties and reflect the relational power dynamics between organizational decision-makers and front-line workers. As shown in Table 1, perceptions of helpfulness are negatively correlated with both automation anxiety and overpayment anxiety. Yet, perceptions of helpfulness were not significantly related to perceptions that the job will change and automation will increase. As industries increasingly adopt automation, it is crucial for decision makers to be aware of potential anxieties that can reduce the perceived helpfulness of technology. For managers hoping to implement automation, this finding signals a need to assess perceptions that the technologies might replace workers as part of the persuasive campaign to increase adoption of automated technologies. Certainly, this validates the argument by HMC scholars that perceptions of technological partners have meaningful consequences for our subsequent 
communication with and about such technologies (Fortunati \& Edwards, 2020); indeed, this argument seems salient for the impending future of work.

\section{Conclusion and Limitations}

This study extends our understanding of how technological change prompts feelings of anxiety among both high- and low-skilled workers. While our study offers insights to a racially White but relatively diversified socioeconomic groups, in a recently automated sector, the specific context also limits the generalizability of these findings. For these workers feelings of automation anxiety predicted variance in perceptions of the near future and the helpfulness of automation. The measures were limited by relatively few items for each construct. Mental models represent an abstract preconception, certainly these mental models could be tied to a wide variety of antecedents and experiences. Future research will benefit from mapping the constellation of both the content and structure of these mental models, beyond the SBTC hypothesis, to better understand antecedents and outcomes for technological concern (see also Banks, 2020).

In all, this study enhances scholarly understanding of how feelings of anxiety affect cognitive mental models, which inform HMC. The future will inevitably include increased automation; thus, perceptions of that process deserve continued scholarly attention. We argue scholars and practitioners ought to attend to automation and overpayment anxieties as they directly connect to feelings about the future and the mental models which permeate everyday communication and work, especially in complex HMC situations.

\section{Author Biographies}

Cameron W. Piercy (PhD) is an assistant professor in the Department of Communication Studies at the University of Kansas and the founding director of the Human-Machine Communication Lab (https://hmc.ku.edu). His research explores how technology is (re) shaping social networks. He is especially interested in how perceptions of technology affect the way people engage with both technologies and other people. His research has been published in Communication Research, Computers in Human Behavior, and New Media \& Society, among others.

\section{https://orcid.org/0000-0003-1431-3086}

Angela N. Gist-Mackey (PhD) is an assistant professor in the Department of Communication Studies at the University of Kansas with expertise in organizational communication. She is largely an interpretive critical scholar who researches issues of social mobility, power, and organizing. Her program of research frequently explores topics related to social class and various stigmatized social identities. Much of Dr. Gist-Mackey's research is engaged, qualitative scholarship partnering with local organizations to provide recommendations for their programs. Her scholarship has been published in outlets such as Organization Studies, Communication Monographs, Journal of Applied Communication Research, and Management Communication Quarterly, among others

(D) https://orcid.org/0000-0002-1590-0728 


\section{References}

Acemoglu, D., \& Restrepo, P. (2019). Automation and new tasks: How technology displaces and reinstates labor. Journal of Economic Perspectives, 33(2), 3-30. https://doi. org/10.1257/jep.33.2.3

Albanese, N. P., Rouse, M. J., \& Schlaifer, M. (2010). Scope of contemporary pharmacy practice: Roles, responsibilities, and functions of pharmacists and pharmacy technicians. Journal of the American Pharmacists Association, 50, e35-e69. https://doi.org/10.1331/ JAPhA.2010.10510

Autor, D. H. (2015). Why are there still so many jobs? The history and future of workplace automation. Journal of Economic Perspectives, 29(3), 3-30. https://doi.org/10.1257/ jep.29.3.3

Banks, J. (2020). Optimus primed: Media cultivation of robot mental models and social judgments. Frontiers in Robotics and AI, 7. https://doi.org/10.3389/frobt.2020.00062

Barrett, M., Oborn, E., Orlikowski, W. J., \& Yates, J. (2012). Reconfiguring boundary relations: Robotic innovations in pharmacy work. Organization Science, 23, 1448-1466. https://doi.org/10.1287/orsc.1100.0639

Baym, N. K. (2015). Personal connections in the digital age. John Wiley \& Sons.

Berman, E., Bound, J., \& Machin, S. (1998). Implications of skill-biased technological change: International evidence. The Quarterly Journal of Economics, 113, 1245-1279. https://doi.org/10.1162/003355398555892

Brehm, J. W., \& Cohen, A. R. (1962). Explorations in cognitive dissonance. Wiley \& Sons.

Brynjolfsson, E., \& Mitchell, T. (2017). What can machine learning do? Workforce implications. Science, 358, 1530-1534. https://doi.org/10.1126/science.aap8062

BusinessWire. (2020, February 3). Walgreens boots alliance advances transformation of its global information technology operating model to accelerate digitalization, drive efficiencies and savings. https://web.archive.org/web/20200713130332/https://www. businesswire.com/news/home/20200203005432/en/Walgreens-Boots-Alliance-AdvancesTransformation-Global-Information

Chapuis, C., Roustit, M., Bal, G., Schwebel, C., Pansu, P., David-Tchouda, S., Foroni, L., Calop, J., Timsit, J.-F., Allenet, B., Bosson, J.-L., \& Bedouch, P. (2010). Automated drug dispensing system reduces medication errors in an intensive care setting. Critical Care Medicine, 38, 2275-2281. https://doi.org/10.1097/CCM.0b013e3181f8569b

Colbert, A., Yee, N., \& George, G. (2016). The digital workforce and the workplace of the future. Academy of Management Journal, 59, 731-739. https://doi.org/10.5465/ amj.2016.4003

Desselle, S. P., \& Holmes, E. R. (2017). Results of the 2015 national certified pharmacy technician workforce survey. American Journal of Health-System Pharmacy, 74, 981-991. https://doi.org/10.2146/ajhp160666

Edwards, A., Edwards, C., Westerman, D., \& Spence, P. R. (2019). Initial expectations, interactions, and beyond with social robots. Computers in Human Behavior, 90, 308-314. https://doi.org/10.1016/j.chb.2018.08.042

Elder, M. (2019, September). Pharmacy Automation Technology Market Size and Research Report. BCC Research. https://web.archive.org/web/20200713135920/https://www.bcc research.com/market-research/instrumentation-and-sensors/pharmacy-automation-techmarkets-report.html 
Fairhurst, G. T. (2010). The power of framing: Creating the language ofleadership. John Wiley \& Sons.

Fanning, L., Jones, N., Grand Dip Clinical Pharmacy, \& Manias, E. (2016). Impact of automated dispensing cabinets on medication selection and preparation error rates in an emergency department: A prospective and direct observational before-and-after study. Journal of Evaluation in Clinical Practice, 22, 156-163. https://doi.org/10.1111/jep.12445

Fortunati, L., \& Edwards, A. (2020). Opening space for theoretical, methodological, and empirical issues in human-machine communication. Human-Machine Communication, 1. https://doi.org/10.30658/hmc.1.1

Frank, M. R., Autor, D., Bessen, J. E., Brynjolfsson, E., Cebrian, M., Deming, D. J., Feldman, M., Groh, M., Lobo, J., Moro, E., Wang, D., Youn, H., \& Rahwan, I. (2019). Toward understanding the impact of artificial intelligence on labor. Proceedings of the National Academy of Sciences, 116, 6531-6539. https://doi.org/10.1073/pnas.1900949116

Frey, C. B., \& Osborne, M. A. (2017). The future of employment: How susceptible are jobs to computerisation? Technological Forecasting and Social Change, 114, 254-280. https:// doi.org/10.1016/j.techfore.2016.08.019

Gebhart, F. (2019, July 4). The Future of Pharmacy Automation. Drug Topics. https://web. archive.org/web/20201010183848/https://www.drugtopics.com/view/future-pharmacyautomation

Geiger, A. W. (2019, April 8). How Americans see automation and the workplace|Pew Research Center. Pew Research. https://web.archive.org/web/20190530220726/https:// www.pewresearch.org/fact-tank/2019/04/08/how-americans-see-automation-and-theworkplace-in-7-charts

Gorbach, C., Blanton, L., Lukawski, B. A., Varkey, A. C., Pitman, E. P., \& Garey, K. W. (2015). Frequency of and risk factors for medication errors by pharmacists during order verification in a tertiary care medical center. American Journal of Health-System Pharmacy, 72, 1471-1474. https://doi.org/10.2146/ajhp140673

Green, M. C., \& Clark, J. L. (2015). Real or ersatz? Determinants of benefits and costs of online social interactions. In S. Sundar (ed.), The Handbook of the Psychology of Communication Technology (pp. 247-269). Wiley Blackwell. https://doi.org/10.1002/9781118426456. ch11

Horstmann, A. C., \& Krämer, N. C. (2019). Great expectations? Relation of previous experiences with social robots in real life or in the media and expectancies based on qualitative and quantitative assessment. Frontiers in Psychology, 10. https://doi.org/10.3389/ fpsyg.2019.00939

Hynniman, C. E., \& Lamy, P. P. (1967). Outpatient pharmacy automation. American Journal of Hospital Pharmacy, 24, 18-21. https://doi.org/10.1093/ajhp/24.1.18

Kline, R. B. (2015). Principles and practice of structural equation modeling. Guilford Press.

Kühne, R. (2013). Testing measurement invariance in media psychological research. Journal of Media Psychology, 25, 153-159. https://doi.org/10.1027/1864-1105/a000096

Leonardi, P. M. (2012). Car crashes without cars: Lessons about simulation technology and organizational change from automotive design. MIT Press.

Liang, Y., \& Lee, S. A. L. (2017). Fear of autonomous robots and artificial intelligence: Evidence from national representative data with probability sampling. International Journal of Social Robotics, 9, 379-384. https://doi.org/10.1007/s12369-017-0401-3 
Littler, C. R., \& Innes, P. (2003). Downsizing and deknowledging the firm. Work, Employment and Society, 17, 73-100. https://doi.org/10.1177/0950017003017001263

Madden, E. E., \& Dreyfus, R. H. (1968). Outpatient pharmacy prescription automation. American Journal of Hospital Pharmacy, 25, 20-25. https://doi.org/10.1093/ajhp/25.1.20a

Mantovani, G. (1996). Social context in HCl: A new framework for mental models, cooperation, and communication. Cognitive Science, 20, 237-269. https://doi.org/10.1207/ s15516709cog2002_3

O*Net. (2020, July 7). Summary report for: 29-2052.00-Pharmacy Technicians. https://web. archive.org/web/20200528144913/https://www.onetonline.org/link/summary/29-2052.00

Polgreen, L. A., Mott, D. A., \& Doucette, W. R. (2011). An examination of pharmacists' labor supply and wages. Research in Social and Administrative Pharmacy, 7(4), 406-414. https://doi.org/10.1016/j.sapharm.2010.10.006

Putnick, D. L., \& Bornstein, M. H. (2016). Measurement invariance conventions and reporting: The state of the art and future directions for psychological research. Developmental Review, 41, 71-90. https://doi.org/10.1016/j.dr.2016.06.004

Rosseel, Y. (2012). lavaan: An R package for structural equation modeling. Journal of Statistical Software, 48, 1-36. https://doi.org/10.18637/jss.v048.i02

Smith, A. (2016). Public Predictions for the Future of Workforce Automation Pew Research. https://web.archive.org/web/20210110192739/https://www.pewresearch.org/internet/ 2016/03/10/public-predictions-for-the-future-of-workforce-automation

Spence, P. R., Westerman, D., \& Lin, X. (2018). A robot will take your job. How does that make you feel? Examining perceptions of robots in the workplace. In A. L. Guzman (Ed.), Human-Machine Communication: Rethinking communication, technology, and ourselves (pp. 185-200). Peter Lang.

Spinks, J., Jackson, J., Kirkpatrick, C. M., \& Wheeler, A. J. (2017). Disruptive innovation in community pharmacy - Impact of automation on the pharmacist workforce. Research in Social and Administrative Pharmacy, 13, 394-397. https://doi.org/10.1016/j. sapharm.2016.04.009

Tabachnick, B. G., \& Fidell, L. S. (2019). Using multivariate statistics (7th ed.). Pearson.

Taipale, S. de Luca, F., Sarrica, M., \& Fortunati, L. (2015). Robot shift from industrial production to social reproduction. In J. Vincent, S. Taipale, B. Sapio, G. Lugano, \& L. Fortunati (Eds.) Social Robots from a Human Perspective (pp. 11-24). Springer.

Taipale, S., \& Fortunati, L. (2018). Communicating with machines: Robots as the next new media. In A. L. Guzman (Ed.), Human-Machine Communication: Rethinking communication, technology, and ourselves (pp. 201-219). Peter Lang.

Turja, T., \& Oksanen, A. (2019). Robot acceptance at work: A multilevel analysis based on 27 EU countries. International Journal of Social Robotics, 11, 679-689. https://doi. org/10.1007/s12369-019-00526-x

Walsh, K. E., Chui, M. A., Kieser, M. A., Williams, S. M., Sutter, S. L., \& Sutter, J. G. (2011). Exploring the impact of an automated prescription-filling device on community pharmacy technician workflow. Journal of the American Pharmacists Association, 51(5), 613-618. https://doi.org/10.1331/JAPhA.2011.09166

West, D. M. (2018). The future of work: Robots, AI, and automation. Brookings Institution Press. 
Wheeler, J. S., Renfro, C. P., Wang, J., Qiao, Y., \& Hohmeier, K. C. (2019). Assessing pharmacy technician certification: A national survey comparing certified and noncertified pharmacy technicians. Journal of the American Pharmacists Association, 59(3), 369374.e2. https://doi.org/10.1016/j.japh.2018.12.021

Wike, R., \& Stokes, B. (2018). In advanced and emerging economies alike, worries about job automation. Pew Research. https://web.archive.org/web/20200713140521/https://www. pewresearch.org/global/wp-content/uploads/sites/2/2018/09/Pew-Research-Center_ In-Advanced-and-Emerging-Economies-Alike-Worries-about-Job-Automation_2018-09-13. pdf 